\title{
MHC class II transactivator CIITA induces cell resistance to Ebola virus and SARS-like coronaviruses
}

\author{
Anna Bruchez ${ }^{1 * \dagger}$, Ky Sha ${ }^{1 *}$, Joshua Johnson ${ }^{2}+$, Li Chen $^{3}$, Caroline Stefani', Hannah McConnell ${ }^{1}$, Lea \\ Gaucherand $^{1}$, Rachel Prins ${ }^{1}$, Kenneth A. Matreyek ${ }^{4}+$, Adam J. Hume ${ }^{5,6}$, Elke Mühlberger ${ }^{5,6}$, Emmett V. \\ Schmidt $^{7}$, Gene G. Olinger ${ }^{2,5,6,8}$, Lynda M. Stuart ${ }^{1,9}$, Adam Lacy-Hulbert ${ }^{1,10}$ \#
}

${ }^{1}$ Benaroya Research Institute, Seattle, WA 98101, USA. ${ }^{2}$ National Institute of Allergy and Infectious Diseases (NIAID) Integrated Research Facility, Frederick, MD 21702, USA ${ }^{3}$ Massachusetts General Hospital, Boston, MA 02114, USA. ${ }^{4}$ Department of Genome Sciences, University of Washington, Seattle, WA 98109, USA. ${ }^{5}$ Boston University School of Medicine, Boston, MA 02118, USA. ${ }^{6}$ National Emerging Infectious Diseases Laboratories, Boston University, Boston, MA 02118, USA. ${ }^{7}$ Merck and Co., Inc, Kenilworth, NJ 07033, USA. ${ }^{8}$ MRIGlobal, Gaithersburg, MD 20878, USA. ${ }^{9}$ Bill and Melinda Gates Foundation, Seattle, WA 98109, USA. ${ }^{10}$ Department of Immunology, University of Washington, Seattle, WA 98109, USA.

*These authors contributed equally to this work. †Present address: Department of Pathology, Case Western Reserve University, Cleveland, OH 44106, USA. łPresent address: AbViro LLC, Bethesda, MD 20814, USA. §Present address: Division of Basic Sciences, Fred Hutchinson Cancer Research Center, Seattle, WA 98109 , USA. ๆPresent address: Graduate Program in Molecular Microbiology, Tufts Graduate School of Biomedical Sciences and Department of Molecular Biology and Microbiology, Tufts University, Boston, MA 02155, USA.

\#Corresponding author. Email: alacyhulbert@benaroyaresearch.org

Recent outbreaks of Ebola virus (EBOV) and SARS-CoV-2 have exposed our limited therapeutic options and poor understanding of cellular mechanisms that block viral infections. Using a transposon-mediated geneactivation screen in human cells, we identify that the MHC class II transactivator (CIITA) has antiviral activity against EBOV. CIITA induces resistance by activating expression of the p41 isoform of invariant chain CD74, which inhibits viral entry by blocking cathepsin-mediated processing of the Ebola glycoprotein (EboGP). We further show that CD74 p41 can block the endosomal entry pathway of coronaviruses, including SARS-CoV-2. These data therefore implicate CIITA and CD74 in host defense against a range of viruses, and identify an additional function of these proteins beyond their canonical roles in antigen presentation.

Recent and ongoing outbreaks of Ebola virus (EBOV) in Africa (1) and the SARS-CoV-2 pandemic highlight the need to identify additional treatment strategies for viral infections, including approaches that might complement traditional antivirals. Of particular interest is the identification of host-directed therapies that target common vulnerabilities and may be potentially efficacious against multiple viruses, including those that may emerge in the future.

We set out to identify host pathways of cellular resistance to pathogens with pandemic potential, using a transposonmutagenesis forward genetic approach. We used a modified PiggyBac (PB) transposon (Fig. 1A), which stimulates or disrupts expression of neighboring genes, allowing an interrogation of both gene activation and inactivation in a single screen (2). Transposon-mutagenized libraries were treated with Ebola glycoprotein (EboGP)-expressing recombinant vesicular stomatitis virus (referred to as EboGP-VSV). Susceptible wild-type (wt) U2OS cells died after 3-4 days of treatment, whereas surviving cells could be expanded from mutagenized libraries and exhibited stable resistance to re-challenge with EboGP-VSV (Fig. 1B). These cells showed no cross-resistance to VSV containing the VSV glycoprotein (VSVg-VSV) (Fig. 1C), suggesting that the majority of resistance mechanisms selected in this screen targeted EboGP-mediated entry.

We identified candidate resistance genes by identifying genomic regions with high numbers of transposon insertions ("common insertion sites" or CISs) (3). Combining data from eight independent screens revealed seven genomic loci with highly statistically significant $\left(p<10^{-8}\right)$ CISs that occurred in more than one screen, representing high-confidence candidate-resistance mutations (Fig. 1D, outer ring). Likely target genes of transposon insertions were identified based on transposon insertion position and orientation (Fig. 1D and table S1). We focused on the two genes found in all eight screens using the most stringent criteria.

The first of these was NPC1, located on chromosome 18. All transposon insertions at this site were intragenic, in both sense and anti-sense orientations and were predicted to disrupt $\mathrm{NPCl}$ expression (Fig. 1E). This is consistent with the role of $\mathrm{NPC1}$ as the EBOV receptor $(4,5)$ and validates our screening approach. Notably, U2OS cells are haploid at the $N P C 1$ locus (6) and these transposon insertions are therefore predicted to generate NPC1-null cells, explaining why NPC1 was the only predicted gene-disruption mutant identified as a high-stringency candidate gene.

All transposon insertions at the second CIS, on 
chromosome 16, were upstream of the gene CIITA, and were all oriented in the sense orientation, consistent with activation of expression (Fig. 1F and fig. S1). CIITA overexpression in wt U2OS cells increased cell survival, reduced GFP reporter expression, and completely inhibited plaque formation, confirming that CIITA increases resistance to EboGP-VSV 1001000-fold (Fig. 2, A to E, and fig. S2). CIITA-overexpressing cells were also resistant to EboGP-pseudotyped single cycle viruses (Fig. 2, F and G), strongly suggesting that CIITA inhibits viral entry rather than targeting viral transactivators as suggested for HIV and $\operatorname{HTLV}(7,8)$. Furthermore, using EboGP-virus like particles (EboGP-VLPs) carrying $\beta$-lactamase (BLAM) (9), we found that CIITA did not affect the internalization of EboGP-VLPs into cells (Fig. $2 \mathrm{H}$ ), but blocked viral fusion, which occurs in the endosome (10) (Fig. 2I). CIITA-expressing U2OS cells were also highly resistant to infection by high-titers of native EBOV, showing reduced reporter gene expression, cell death, and plaque formation (Fig. 2 , $\mathrm{J}$ to $\mathrm{M}$ ). CIITA expression did not inhibit replication of an EBOV minigenome, indicating that CIITA does not act on the viral replication complex (fig. S3). Furthermore, CIITA inhibited infection mediated by GPs from a range of EBOV species, including Sudan, Zaire, and Reston, as well as the distantly related filovirus Marburg virus (Fig. 2G). Thus, CIITA induces broad antiviral activity against EBOV and other pathogenic filoviruses through the inhibition of viral GP-mediated entry.

CIITA, also known as NLRA, is a Nod-like receptor (NLR) (11), but unlike most other NLRs, which function as cytosolic sensors, CIITA is a transcription factor (12). We therefore hypothesized that its antiviral activity occurred through the altered expression of host target genes. Supporting this hypothesis, mutation of domains required for transcriptional activity completely ablated CIITA antiviral activity (fig. S4). Resistance also required NF-Y, a component of the enhanceosome multi-protein complex, which mediates transcriptional activation by CIITA (13), but was independent of another enhanceosome protein, RFX5 (figs. S4 and S5). Antiviral activity was therefore mediated by a subset of NF-Ydependent RFX5-independent CIITA target genes, which include genes associated with antiviral immunity (14). Systematic knock-down of all CIITA target genes identified a single gene, CD74, required for CIITA-mediated resistance (Fig. 3, A and B). This was confirmed by CRISPR knockout (ko) of CD74 expression and function in CIITA-overexpressing cells (Fig. $3 \mathrm{C})$.

Both CIITA and CD74 are expressed at high levels by macrophages and dendritic cells (DCs), which are early targets of $\operatorname{EBOV}(15,16)$. To test whether CIITA has antiviral activity in immune cells, we used primary bone marrow-derived macrophages (BMDMs) from $\mathrm{Ciita}^{-/-}$and $\mathrm{Cd}^{-4^{-/-}}$mice. Naïve BMDMs did not express high levels of CIITA or CD74, and showed no difference in viral fusion. Treatment with IFN- $\gamma$ and LPS induced expression of CIITA and CD74, and IFNҮ/LPS primed $\mathrm{Ciita}^{-/-}$and $\mathrm{Cd} 74^{-/-}$BMDMs had higher levels of EboGP-VLP fusion than in equivalent wt cells (Fig. 3, D to $\mathrm{G}$, and fig. S6). Similar results were seen in $\mathrm{Cd}_{44^{-/-}}$bone marrow-derived DCs and in a $C D 74^{-/-}$human macrophage-like cell line (differentiated THP-1) (figs. S7 and S8). Thus, endogenous CIITA and CD74 have antiviral activity in primary immune cells, which can be induced by exposure to IFN- $\gamma$ and LPS.

CD74 is the MHC-II invariant chain and human cells express four main isoforms of CD74, differing by the presence of a N-terminal ER-retention signal and an internal thyroglobulin domain (Fig. 4A) (17). Only one CD74 isoform, p41, was able to fully rescue resistance to EboGP-VSV infection in CIITA-expressing, CD74-knockout cells (Fig. 4B and fig. S9). p41 conferred resistance independently of CIITA expression (Fig. 4C), demonstrating that CD74 p41 expression was sufficient to induce antiviral activity. This property of CD74 was not limited to U2OS cells, as CD74 p41 similarly inhibited fusion when expressed in THP-1 cells (Fig. 4D). The p41 isoform contains the thyroglobulin domain, lacks the ER retention signal, and normally accumulates in endosomes. Mutant constructs of $\mathrm{CD} 74$ revealed that only the thyroglobulin domain is essential for antiviral activity, but dissociation from the membrane, either by addition of a furin cleavage site ("furin") or deletion of the transmembrane sequence ("No TM"), or delivery to the cell surface, by fusion to a heterologous cytoplasmic and transmembrane sequence from tetherin ("tetherin"; Fig. 4E) almost completely removed antiviral activity (Fig. 4E and fig. S10). Thus, antiviral activity required delivery of the thyroglobulin domain to the endosomal membrane. Electron microscopy showed that EboGP-VSV virions accumulated in late endosomal multivesicular bodies (MVBs) of CIITA- and CD74p41-expressing cells, with some virions within intraluminal vesicles (Fig. 4F and fig. S11). Confocal microscopy confirmed that VLPs localized proximal to CD63 and the ESCRT component Hrs which mark MVBs $(18,19)$ (Fig. 4, G and H). Thus, CIITA and CD74 p41 inhibit fusion by arresting viral particles in MVB compartments.

EBOV entry requires endosomal cathepsins $(4,10,20)$ (fig. S12), which sequentially process EboGP (Fig. 4I and fig. S13). The CD74 thyroglobulin domain inhibits cathepsins (21), suggesting that this may be the mechanism for antiviral activity. In support of this, CD74 inhibited EboGP processing, similar to the effects of the cathepsin L (CTSL) inhibitor FYDMK (Fig. 4I). Additionally, disruption of the p41 CTSL binding site (22, 23) by mutation completely inhibited antiviral activity (Fig. $4 \mathrm{~J}$ and fig. S10). Glycoprotein cleavage by endosomal proteases is critical for the entry of other viruses, including coronaviruses. SARS-CoV and SARS-CoV-2 S proteins can be processed by either endosomal cathepsin B and L, or alternatively by cell-surface serine proteases including TMPRSS2 
$(24,25)$. In TMPRSS-expressing cells, such as lung epithelium, inhibition of both cathepsins and serine proteases is required to inhibit viral entry, whereas cathepsin inhibitors alone block infection in cell lines, such as U2OS and Vero cells, that lack TMPRSS2 (25). p41 inhibited entry of viruses pseudotyped with $\mathrm{S}$ proteins from SARS-CoV and a related bat virus WIV1-CoV into U2OS cells, demonstrating that p41 inhibited $\mathrm{S}$ protein processing (Fig. $4 \mathrm{~K}$ ). To determine whether p41 exhibited antiviral activity against authentic SARS coronavirus, we challenged p41-expressing Vero E6 cells with SARS-CoV-2. CD74 p41 expression completely inhibited plaque formation, demonstrating that this antiviral activity extended beyond filoviruses (Fig. 4L).

In summary, we identify the antiviral activity of CIITA and CD74. We show that CIITA induces resistance by up-regulation of the p41 isoform of CD74, which blocks cathepsinmediated cleavage of viral glycoproteins, preventing viral fusion. This antiviral activity protects against a wide range of cathepsin-dependent viruses, including filoviruses and coronaviruses, functions in macrophages and DCs that are early targets of infection $(15,16)$, and is activated by IFN-Y. We demonstrate that CIITA and CD74 mediate the endosomal sequestration of certain viruses as a mechanism of cellular host defense. We speculate that this activity has been co-opted through evolution to facilitate antigen processing and preceded their better-known role in antigen processing, a process that sits at the intersection of innate and adaptive immunity. We anticipate that the application of this transposon screening approach to other models of infection will reveal other mechanisms that have eluded conventional screening strategies.

\section{REFERENCES AND NOTES}

1. S. K. Gire, A. Goba, K. G. Andersen, R. S. G. Sealfon, D. J. Park, L. Kanneh, S. Jalloh, M. Momoh, M. Fullah, G. Dudas, S. Wohl, L. M. Moses, N. L. Yozwiak, S. Winnicki, C. B. Matranga, C. M. Malboeuf, J. Qu, A. D. Gladden, S. F. Schaffner, X. Yang, P.P. Jiang, M. Nekoui, A. Colubri, M. R. Coomber, M. Fonnie, A. Moigboi, M. Gbakie, F. K. Kamara, V. Tucker, E. Konuwa, S. Saffa, J. Sellu, A. A. Jalloh, A. Kovoma, J. Koninga, I. Mustapha, K. Kargbo, M. Foday, M. Yillah, F. Kanneh, W. Robert, J. L. B. Massally, S. B. Chapman, J. Bochicchio, C. Murphy, C. Nusbaum, S. Young, B. W. Birren, D. S. Grant, J. S. Scheiffelin, E. S. Lander, C. Happi, S. M. Gevao, A. Gnirke, A. Rambaut, R. F. Garry, S. H. Khan, P. C. Sabeti, Genomic surveillance elucidates Ebola virus origin and transmission during the 2014 outbreak. Science 345, 13691372 (2014). doi:10.1126/science.1259657 Medline

2. L. Chen, L. Stuart, T. K. Ohsumi, S. Burgess, G. K. Varshney, A. Dastur, M. Borowsky, C. Benes, A. Lacy-Hulbert, E. V. Schmidt, Transposon activation mutagenesis as a screening tool for identifying resistance to cancer therapeutics. BMC Cancer 13, 93 (2013). doi:10.1186/1471-2407-13-93 Medline

3. T. L. Bergemann, T. K. Starr, H. Yu, M. Steinbach, J. Erdmann, Y. Chen, R. T. Cormier, D. A. Largaespada, K. A. T. Silverstein, New methods for finding common insertion sites and co-occurring common insertion sites in transposon- and virus-based genetic screens. Nucleic Acids Res. 40, 3822-3833 (2012). doi:10.1093/nar/gkr1295 Medline

4. M. Côté, J. Misasi, T. Ren, A. Bruchez, K. Lee, C. M. Filone, L. Hensley, Q. Li, D. Ory, K. Chandran, J. Cunningham, Small molecule inhibitors reveal Niemann-Pick $\mathrm{Cl}$ is essential for Ebola virus infection. Nature 477, 344-348 (2011). do:i:10.1038/nature10380 Medline
5. J. E. Carette, M. Raaben, A. C. Wong, A. S. Herbert, G. Obernosterer, N. Mulherkar, A. I. Kuehne, P. J. Kranzusch, A. M. Griffin, G. Ruthel, P. Dal Cin, J. M. Dye, S. P. Whelan, K. Chandran, T. R. Brummelkamp, Ebola virus entry requires the cholesterol transporter Niemann-Pick C1. Nature 477, 340-343 (2011). doi:10.1038/nature10348 Medline

6. J. Barretina, G. Caponigro, N. Stransky, K. Venkatesan, A. A. Margolin, S. Kim, C. J. Wilson, J. Lehár, G. V. Kryukov, D. Sonkin, A. Reddy, M. Liu, L. Murray, M. F. Berger, J. E. Monahan, P. Morais, J. Meltzer, A. Korejwa, J. Jané-Valbuena, F. A. Mapa, J. Thibault, E. Bric-Furlong, P. Raman, A. Shipway, I. H. Engels, J. Cheng, G. K. Yu, J. Yu, P. Aspesi Jr., M. de Silva, K. Jagtap, M. D. Jones, L. Wang, C. Hatton, E. Palescandolo, S. Gupta, S. Mahan, C. Sougnez, R. C. Onofrio, T. Liefeld, L. MacConaill, W. Winckler, M. Reich, N. Li, J. P. Mesirov, S. B. Gabriel, G. Getz, K. Ardlie, V. Chan, V. E. Myer, B. L. Weber, J. Porter, M. Warmuth, P. Finan, J. L. Harris, M. Meyerson, T. R. Golub, M. P. Morrissey, W. R. Sellers, R. Schlegel, L. A. Garraway, The Cancer Cell Line Encyclopedia enables predictive modelling of anticancer drug sensitivity. Nature 483, 603-607 (2012). doi:10.1038/nature11003 Medline

7. H. Okamoto, K. Asamitsu, H. Nishimura, N. Kamatani, T. Okamoto, Reciprocal modulation of transcriptional activities between HIV-1 Tat and MHC class II transactivator CIITA. Biochem. Biophys. Res. Commun. 279, 494-499 (2000). doi:10.1006/bbrc.2000.3972 Medline

8. G. Tosi, E. Pilotti, L. Mortara, A. De Lerma Barbaro, C. Casoli, R. S. Accolla, Inhibition of human T cell leukemia virus type 2 replication by the suppressive action of class II transactivator and nuclear factor Y. Proc. Natl. Acad. Sci. U.S.A. 103, 1286112866 (2006). doi:10.1073/pnas.0601589103 Medline

9. C. J. Shoemaker, K. L. Schornberg, S. E. Delos, C. Scully, H. Pajouhesh, G. G. Olinger, L. M. Johansen, J. M. White, Multiple cationic amphiphiles induce a Niemann-Pick C phenotype and inhibit Ebola virus entry and infection. PLOS ONE 8, e56265 (2013). doi:10.1371/journal.pone.0056265 Medline

10. J. S. Spence, T. B. Krause, E. Mittler, R. K. Jangra, K. Chandran, Direct Visualization of Ebola Virus Fusion Triggering in the Endocytic Pathway. mBio 7, e01857-15 (2016). doi:10.1128/mBio.01857-15 Medline

11. J. A. Harton, M. W. Linhoff, J. Zhang, J. P. Y. Ting, Cutting edge: CATERPILLER: a large family of mammalian genes containing CARD, pyrin, nucleotide-binding, and leucine-rich repeat domains. J. Immunol. 169, 4088-4093 (2002). doi:10.4049/iimmunol.169.8.4088 Medline

12. R. S. Accolla, M. Jotterand-Bellomo, L. Scarpellino, A. Maffei, G. Carra, J. Guardiola, alr-1, a newly found locus on mouse chromosome 16 encoding a trans-acting activator factor for MHC class II gene expression. J. Exp. Med. 164, 369-374 (1986). doi:10.1084/jem.164.1.369 Medline

13. X. S. Zhu, M. W. Linhoff, G. Li, K.-C. Chin, S. N. Maity, J. P.-Y. Ting, Transcriptional scaffold: CIITA interacts with NF-Y, RFX, and CREB to cause stereospecific regulation of the class II major histocompatibility complex promoter. Mol. Cell. Biol. 20, 6051-6061 (2000). doi:10.1128/MCB.20.16.6051-6061.2000 Medline

14. D. Wong, W. Lee, P. Humburg, S. Makino, E. Lau, V. Naranbhai, B. P. Fairfax, K. Chan, K. Plant, J. C. Knight, Genomic mapping of the MHC transactivator CIITA using an integrated ChIP-seq and genetical genomics approach. Genome Biol. 15, 494 (2014). doi:10.1186/s13059-014-0494-z Medline

15. T. W. Geisbert, L. E. Hensley, T. Larsen, H. A. Young, D. S. Reed, J. B. Geisbert, D. P. Scott, E. Kagan, P. B. Jahrling, K. J. Davis, Pathogenesis of Ebola hemorrhagic fever in cynomolgus macaques: Evidence that dendritic cells are early and sustained targets of infection. Am. J. Pathol. 163, 2347-2370 (2003). doi:10.1016/S0002-9440(10)63591-2 Medline

16. M. Bray, T. W. Geisbert, Ebola virus: The role of macrophages and dendritic cells in the pathogenesis of Ebola hemorrhagic fever. Int. J. Biochem. Cell Biol. 37, 15601566 (2005). doi:10.1016/i.biocel.2005.02.018 Medline

17. M. Strubin, C. Berte, B. Mach, Alternative splicing and alternative initiation of translation explain the four forms of the la antigen-associated invariant chain. EMBO J. 5, 3483-3488 (1986). doi:10.1002/i.1460-2075.1986.tb04673.x Medline

18. T. Kobayashi, U. M. Vischer, C. Rosnoblet, C. Lebrand, M. Lindsay, R. G. Parton, E. K. O. Kruithof, J. Gruenberg, The tetraspanin CD63/lamp3 cycles between endocytic and secretory compartments in human endothelial cells. Mol. Biol. Cell 11, 1829-1843 (2000). doi:10.1091/mbc.11.5.1829 Medline

19. K. G. Bache, A. Brech, A. Mehlum, H. Stenmark, Hrs regulates multivesicular body 
formation via ESCRT recruitment to endosomes. J. Cell Biol. 162, 435-442 (2003). doi:10.1083/jcb.200302131 Medline

20. E. H. Miller, G. Obernosterer, M. Raaben, A. S. Herbert, M. S. Deffieu, A. Krishnan, E. Ndungo, R. G. Sandesara, J. E. Carette, A. I. Kuehne, G. Ruthel, S. R. Pfeffer, J. M. Dye, S. P. Whelan, T. R. Brummelkamp, K. Chandran, Ebola virus entry requires the host-programmed recognition of an intracellular receptor. EMBO J. 31, 19471960 (2012). doi:10.1038/emboj.2012.53 Medline

21. M. Mihelič, A. Dobersek, G. Guncar, D. Turk, Inhibitory fragment from the $\mathrm{p} 41$ form of invariant chain can regulate activity of cysteine cathepsins in antigen presentation. J. Biol. Chem. 283, 14453-14460 (2008). doi:10.1074/jbc.M801283200 Medline

22. G. Gunčar, G. Pungerčič, I. Klemenčič, V. Turk, D. Turk, Crystal structure of MHC class II-associated p41 li fragment bound to cathepsin $L$ reveals the structural basis for differentiation between cathepsins L and S. EMBO J. 18, 793-803 (1999). doi:10.1093/emboj/18.4.793 Medline

23. A. M. Lennon-Duménil, R. A. Roberts, K. Valentijn, C. Driessen, H. S. Overkleeft, A. Erickson, P. J. Peters, E. Bikoff, H. L. Ploegh, P. Wolf Bryant, The p41 isoform of invariant chain is a chaperone for cathepsin L. EMBO J. 20, 4055-4064 (2001). doi:10.1093/emboj/20.15.4055 Medline

24. G. Simmons, D. N. Gosalia, A. J. Rennekamp, J. D. Reeves, S. L. Diamond, P. Bates, Inhibitors of cathepsin $\mathrm{L}$ prevent severe acute respiratory syndrome coronavirus entry. Proc. Natl. Acad. Sci. U.S.A. 102, 11876-11881 (2005). doi:10.1073/pnas.0505577102 Medline

25. M. Hoffmann, H. Kleine-Weber, S. Schroeder, N. Krüger, T. Herrler, S. Erichsen, T. S. Schiergens, G. Herrler, N.-H. Wu, A. Nitsche, M. A. Müller, C. Drosten, S. Pöhlmann, SARS-CoV-2 Cell Entry Depends on ACE2 and TMPRSS2 and Is Blocked by a Clinically Proven Protease Inhibitor. Cell 181, 271-280.e8 (2020). doi:10.1016/i.cell.2020.02.052 Medline

26. A. C. Wong, R. G. Sandesara, N. Mulherkar, S. P. Whelan, K. Chandran, A forward genetic strategy reveals destabilizing mutations in the Ebolavirus glycoprotein that alter its protease dependence during cell entry. J. Virol. 84, 163-175 (2010). doi:10.1128/JVI.01832-09 Medline

27. L. T. Jae, M. Raaben, M. Riemersma, E. van Beusekom, V. A. Blomen, A. Velds, R. M. Kerkhoven, J. E. Carette, H. Topaloglu, P. Meinecke, M. W. Wessels, D. J. Lefeber, S. P. Whelan, H. van Bokhoven, T. R. Brummelkamp, Deciphering the glycosylome of dystroglycanopathies using haploid screens for lassa virus entry. Science 340, 479-483 (2013). doi:10.1126/science.1233675 Medline

28. R. Zufferey, D. Nagy, R. J. Mandel, L. Naldini, D. Trono, Multiply attenuated lentiviral vector achieves efficient gene delivery in vivo. Nat. Biotechnol. 15, 871875 (1997). doi:10.1038/nbt0997-871 Medline

29. P. A. Longo, J. M. Kavran, M.-S. Kim, D. J. Leahy, Transient mammalian cell transfection with polyethylenimine (PEI). Methods Enzymol. 529, 227-240 (2013). doi:10.1016/B978-0-12-418687-3.00018-5 Medline

30. Y. Soneoka, P. M. Cannon, E. E. Ramsdale, J. C. Griffiths, G. Romano, S. M. Kingsman, A. J. Kingsman, A transient three-plasmid expression system for the production of high titer retroviral vectors. Nucleic Acids Res. 23, 628-633 (1995). doi:10.1093/nar/23.4.628 Medline

31. T. Hoenen, A. Groseth, J. Callison, A. Takada, H. Feldmann, A novel Ebola virus expressing luciferase allows for rapid and quantitative testing of antivirals. Antiviral Res. 99, 207-213 (2013). doi:10.1016/j.antiviral.2013.05.017 Medline

32. K. Yusa, L. Zhou, M. A. Li, A. Bradley, N. L. Craig, A hyperactive piggyBac transposase for mammalian applications. Proc. Natl. Acad. Sci. U.S.A. 108, 15311536 (2011). doi:10.1073/pnas.1008322108 Medline

33. S. Kanazawa, T. Okamoto, B. M. Peterlin, Tat competes with CIITA for the binding to P-TEFb and blocks the expression of MHC class II genes in HIV infection. Immunity 12, 61-70 (2000). doi:10.1016/S1074-7613(00)80159-4 Medline

34. D. G. Gibson, L. Young, R.-Y. Chuang, J. C. Venter, C. A. Hutchison 3rd, H. O. Smith, Enzymatic assembly of DNA molecules up to several hundred kilobases. Nat. Methods 6, 343-345 (2009). doi:10.1038/nmeth.1318 Medline

35. A. Raval, J. D. Weissman, T. K. Howcroft, D. S. Singer, The GTP-binding domain of class II transactivator regulates its nuclear export. J. Immunol. 170, 922-930 (2003). doi:10.4049/jimmunol.170.2.922 Medline

36. S. Bontron, C. Ucla, B. Mach, V. Steimle, Efficient repression of endogenous major histocompatibility complex class II expression through dominant negative CIITA mutants isolated by a functional selection strategy. Mol. Cell. Biol. 17, 4249-4258
(1997). doi:10.1128/MCB.17.8.4249 Medline

37. E. Campeau, V. E. Ruhl, F. Rodier, C. L. Smith, B. L. Rahmberg, J. O. Fuss, J. Campisi, P. Yaswen, P. K. Cooper, P. D. Kaufman, A versatile viral system for expression and depletion of proteins in mammalian cells. PLOS ONE 4, e6529 (2009). doi:10.1371/journal.pone.0006529 Medline

38. T. Noda, H. Sagara, E. Suzuki, A. Takada, H. Kida, Y. Kawaoka, Ebola virus VP40 drives the formation of virus-like filamentous particles along with GP. J. Virol. 76, 4855-4865 (2002). doi:10.1128/JVI.76.10.4855-4865.2002 Medline

39. B. Manicassamy, L. Rong, Expression of Ebolavirus glycoprotein on the target cells enhances viral entry. Virol. J. 6, 75 (2009). doi:10.1186/1743-422X-6-75 Medline

40. P. Mali, L. Yang, K. M. Esvelt, J. Aach, M. Guell, J. E. DiCarlo, J. E. Norville, G. M. Church, RNA-guided human genome engineering via Cas9. Science 339, 823-826 (2013). doi:10.1126/science.1232033 Medline

41. K. Schornberg, S. Matsuyama, K. Kabsch, S. Delos, A. Bouton, J. White, Role of endosomal cathepsins in entry mediated by the Ebola virus glycoprotein. J. Virol. 80, 4174-4178 (2006). doi:10.1128/JVI.80.8.4174-4178.2006 Medline

42. E. V. Nelson, J. R. Pacheco, A. J. Hume, T. N. Cressey, L. R. Deflubé, J. B. Ruedas, J. H. Connor, H. Ebihara, E. Mühlberger, An RNA polymerase II-driven Ebola virus minigenome system as an advanced tool for antiviral drug screening. Antiviral Res. 146, 21-27 (2017). doi:10.1016/i.antiviral.2017.08.005 Medline

43. E. K. Bikoff, L. Y. Huang, V. Episkopou, J. van Meerwijk, R. N. Germain, E. J. Robertson, Defective major histocompatibility complex class II assembly, transport, peptide acquisition, and CD4+ T cell selection in mice lacking invariant chain expression. J. Exp. Med. 177, 1699-1712 (1993). doi:10.1084/jem.177.6.1699 Medline

\section{ACKNOWLEDGMENTS}

We thank M. Mason, M. Rosasco, S. Presnell, and the Bioinformatics Department at BRI for support in data analysis and V. Gersuk and the BRI genomics core for sequencing. We thank B. Schneider and S. MacFarlane from the Electron Microscopy Resource at Fred Hutch for help with transmission electron microscopy experiments and Dr L. Eisenlohr and M. O'Mara at Children's Hospital of Philadelphia for providing Cd74-knockout mouse bone marrow. Funding: This work was supported by National Institutes of Health grants R33Al102266, U01AI070330 and R33Al119341 (to A.L-H. and L.M.S.), U19AI125378-04S1 (to A.L-H.) and R21Al135912 (to E.M.). Work at NIAID Integrated Research Facility was funded by Contract no. HHSN272200700016I to Battelle Memorial Institute (BMI). J.J. performed this work an employee of Battelle Memorial Institute (BMI). SARS-CoV-2 work was performed in the BSL3 at Case Western Reserve University (CWRU), which is supported by the CWRU and University Hospitals Center for AIDS Research grant P30AI36219. Author contributions: A.B. performed the majority of experiments. Screen and data analysis tools were developed by K.S. BSL4 experiments were performed by J.J. and G.O., minigenome experiments were performed by A.J.H. and E.M., and K.A.M. designed all CD74 and CIITA mutations. H.M., R.P., and L.G. provided technical assistance. C.S. assisted with data analysis and visualization. G.O. and E.M. provided assistance with experimental planning and data interpretation. L.C., E.S., L.S., and A.L-H. conceived the study. The manuscript was written by A.L-H and L.S. with assistance from A.B. and K.S. Competing interests: E.S. is presently an employee of Merck and $\mathrm{Co}$., Inc, Kenilworth, $\mathrm{NJ}$ and holds stock in Merck and Co. This work was conducted prior to E.S.'s affiliation with Merck. Authors declare no other competing interests. Data and materials availability: Full analysis of screen results are presented in the supplementary materials. DNA and RNA sequencing data deposited at GEO (GSE156598 and GSE155204, respectively). The PiggyBAC transposon was obtained under a Material Agreement with the Wellcome Trust Sanger Institute. All other data are available in the manuscript or the supplementary materials. This work is licensed under a Creative Commons Attribution 4.0 International (CC BY 4.0) license, which permits unrestricted use, distribution, and reproduction in any medium, provided the original work is properly cited. To view a copy of this license, visit https://creativecommons.org/licenses/by/4.0/. This license does not apply to figures/photos/artwork or other content included in the article that is credited to a third party; obtain authorization from the rights holder before using such material. 


\section{SUPPLEMENTARY MATERIALS}

science.sciencemag.org/cgi/content/full/science.abb3753/DC1

Materials and Methods

Figs. S1 to S14

Tables S1 to S5

References (26-43)

21 February 2020; accepted 20 August 2020

Published online 27 August 2020

10.1126/science.abb3753 
A

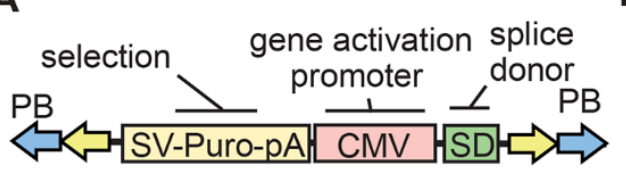

B

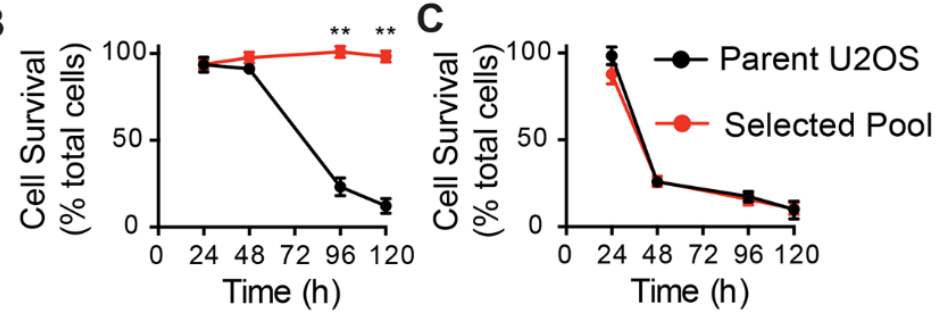

D

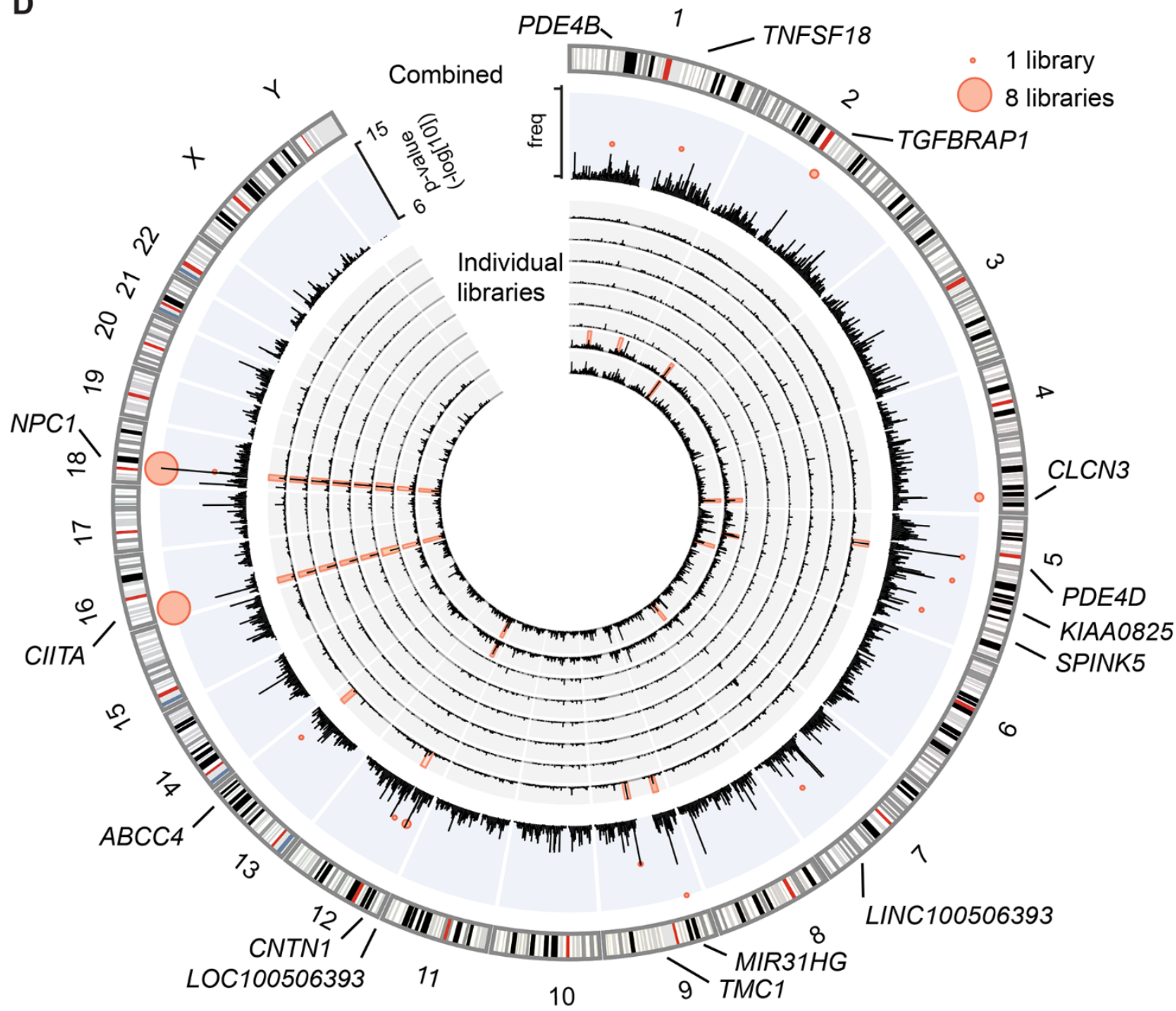

E

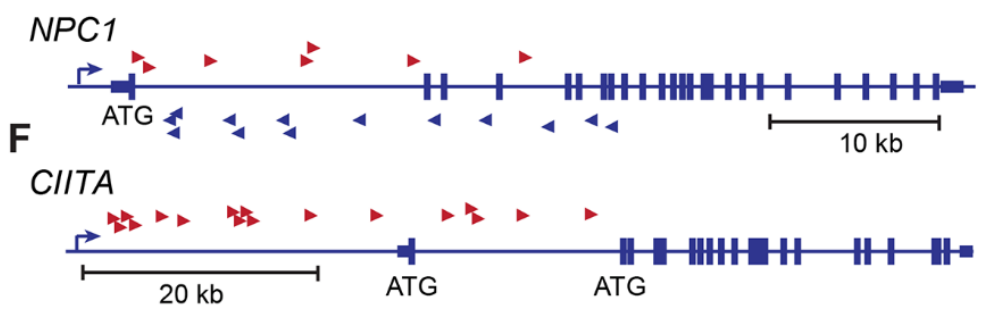

Fig. 1. Transposon-mediated activation-tagging generates mutant cells resistant to Ebola. (A) Modified PiggyBac (PB) transposon. (B and C) Resistance of selected cells to EboGP-VSV (B), and VSVg-VSV (C). Mean $\pm S D$ of $n=3$ replicates for one representative pool. Student's $t$ test, ${ }^{*} P<0.01$. (D) Distribution of transposon insertions. Inner rings show insertions per $1 \mathrm{Mb}$ for individual libraries (black histograms) and common insertion sites $\left(P<10^{-7}\right)$. Outer ring shows combined insertions for all libraries (black histogram) and lowest $P$-value for common insertion sites (red bubble plot). Point size represents number of libraries with common insertion site. (E and $F$ ) Cumulative independent insertions from all eight libraries mapping to NPC1 and CIITA. 

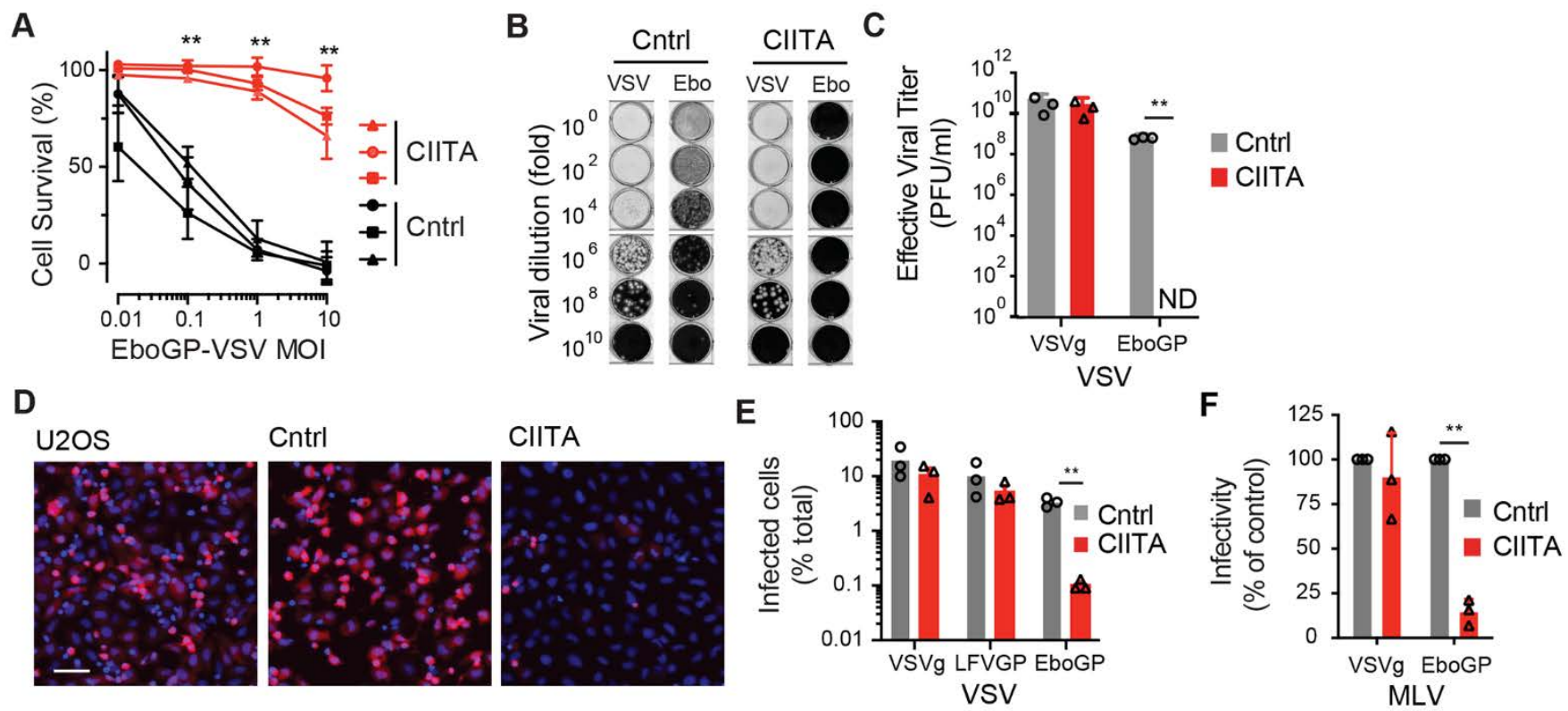

Cntrl
CIITA
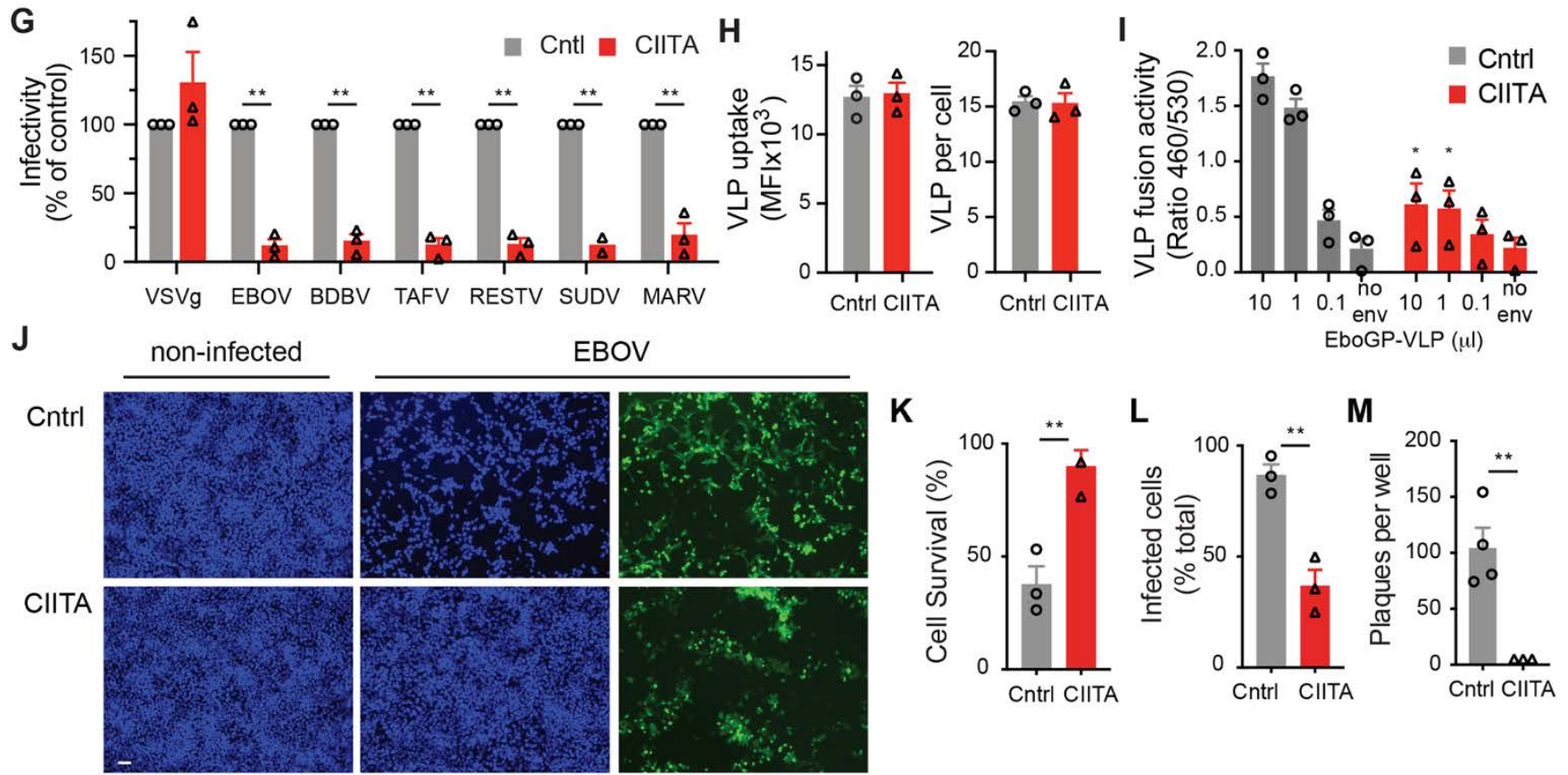

Fig. 2. Identification of CIITA as an Ebola restriction factor. (A) Resistance of CIITA-overexpressing and control U2OS cells EboGP-VSV. (B and C) Plaque formation assays (B) and effective viral titer (C) for control and CIITA-overexpressing U2OS cells infected with VSVg-VSV (VSV) and EboGP-VSV (Ebo). (D) Representative images of CIITA-transfected (CIITA), control-transfected (Cntrl), and unmanipulated U2OS cells (U2OS) infected with mCherry-expressing EboGP-VSV (red) and stained with Hoechst 33342 to resolve cell nuclei (blue). (E to G) Infection of control and CIITA-expressing U2OS cells by EboGP-VSV, LFVGP-VSV, or VSVg-VSV (E), VSVg-MLV and EboGP-MLV (F), or HIV pseudotyped with VSVg or GP from EBOV, Taï Forest virus (TAFV), Bundibugyo virus (BDBV), Sudan virus (SUDV), Reston virus (RESTV), or Marburg virus (MARV) (G). ( $\mathrm{H}$ and $\mathrm{I}$ ) Internalization $(\mathrm{H})$ and fusion (I) of EboGP-VLPs by control and CIITA-overexpressing U2OS cells. No env: non-enveloped control VLPs. ( $\mathrm{J}$ to $\mathrm{M}$ ) Infection of control and CIITA-overexpressing U2OS cells by infectious Ebolavirus (EBOV) measured by imaging of GFP reporter (green) and cell nuclei (blue) $(\mathrm{J})$, cell survival $(K)$, infected cells $(L)$ or plaque formation $(M)$. Data are means \pm SEM of three independent experiments $(A-I)$ or experiments with three independent cell clones (K-M). Student's $t$ test $(A, C, K-M)$ or ANOVA with Tukey's multiple comparison test (E-I); ${ }^{*} P<0.05$; ${ }^{* *} P<0.01$. ND: not detected). Scale bars: $100 \mu \mathrm{m}$. 
A

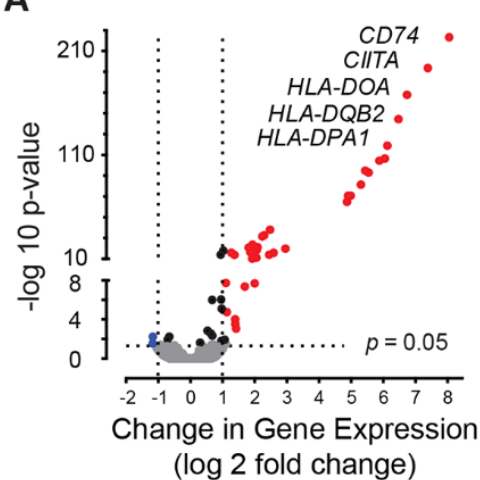

C
B

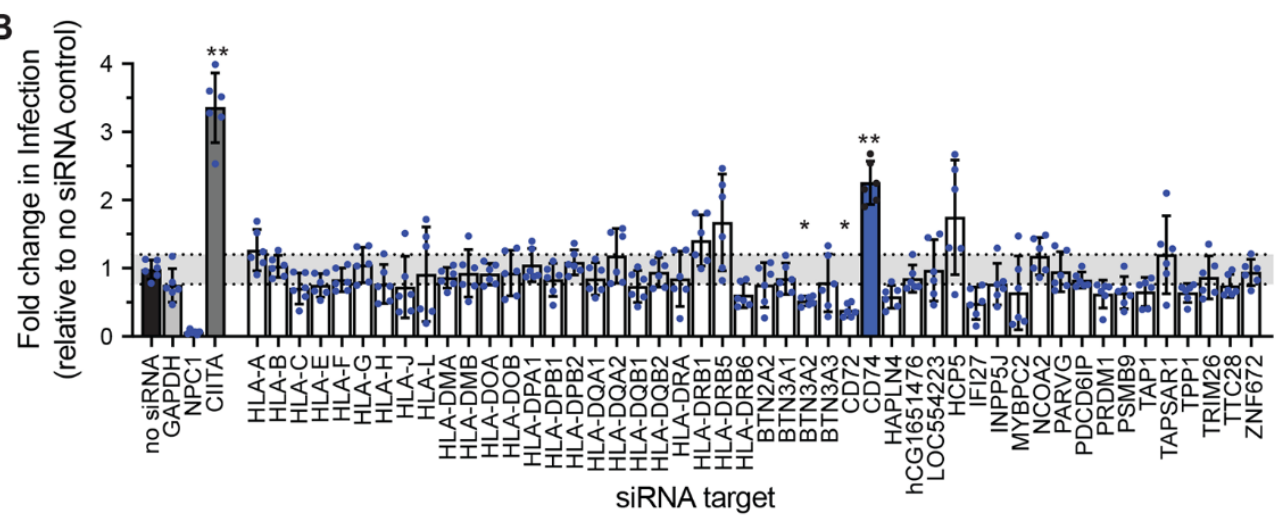

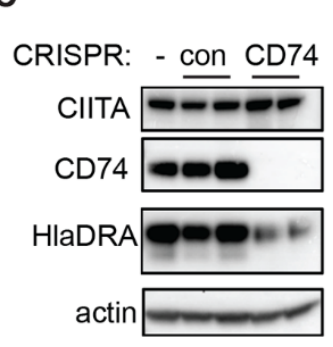
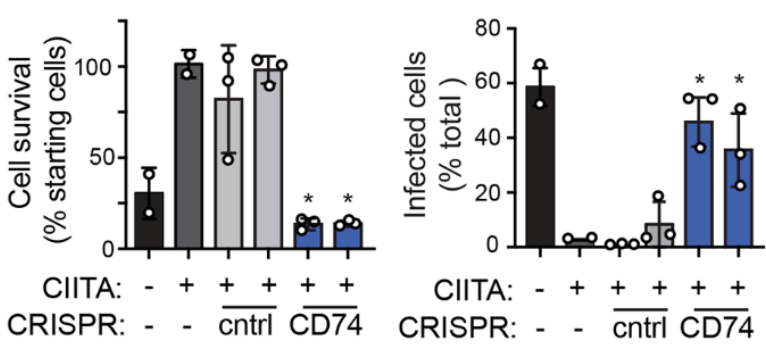

D

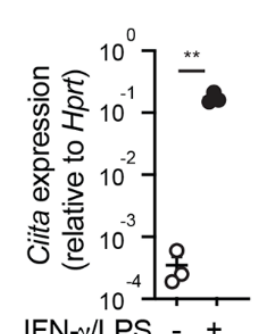

IFN- $\gamma / \mathrm{LPS}-+$
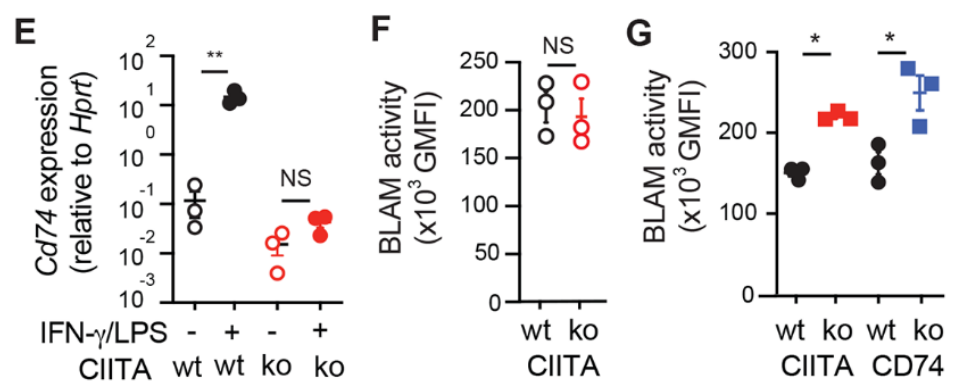

Fig. 3. Transcriptional activity of CIITA and enhanceosome components are required for resistance. (A) Genes regulated by CIITA in U2OS cells, with strongest induced genes identified. Mean of three independent CIITA-expressing clones and controls. (B) EboGP-VSV infection of CIITA-expressing cells treated with siRNA against CIITA transcriptional targets. Data from two siRNAs per gene, $N=3$ independent screens, bars indicate mean with $95 \% \mathrm{Cl}$. One-way ANOVA with Bonferroni's multiple comparisons; ${ }^{*} P<0.05$ and ${ }^{*} P<0.01$. Dotted lines indicate $99 \% \mathrm{Cl}$ from no siRNA control. (C) CD74 CRISPR-targeting in CIITA-overexpressing U2OS cells was verified by immunoblot, and infection and survival measured following EboGP-VSV challenge. Means \pm SEM of $N=3$ experiments using two independent cell clones. ( $D$ and $E$ ) Ciita and Cd74 expression in wt or Ciita ${ }^{-/-}$ mouse BMDMs with or without priming by IFN- $\gamma$ and LPS. ( $F$ and $G$ ) Fusion of EboGP-VLPs in unprimed $(F)$ or primed (G) mouse BMDM from Ciita ${ }^{-/-}$and $\mathrm{Cd}_{74^{-/-}}$mice, measured as geometric mean fluorescence (GMFI) of cleaved CCF2. Means \pm SEM for independent cultures from three mice/group. Student's $t$ test; ${ }^{*} P<0.05$; ${ }^{*} P<0.01$. Similar results were observed in three independent experiments. 


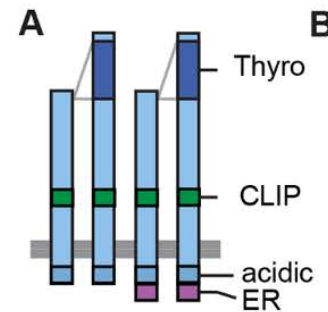

$p^{3^{3}} p^{x^{1}} p^{3^{5}} p^{x^{3}}$

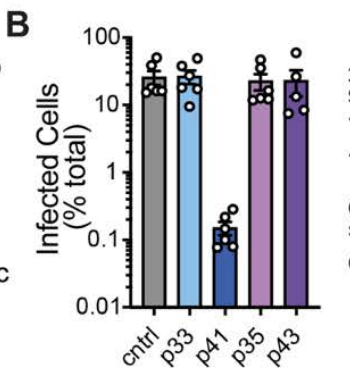

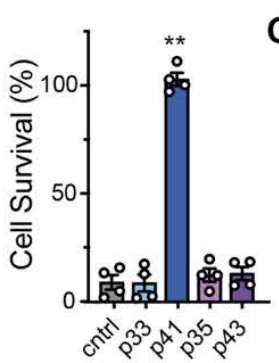
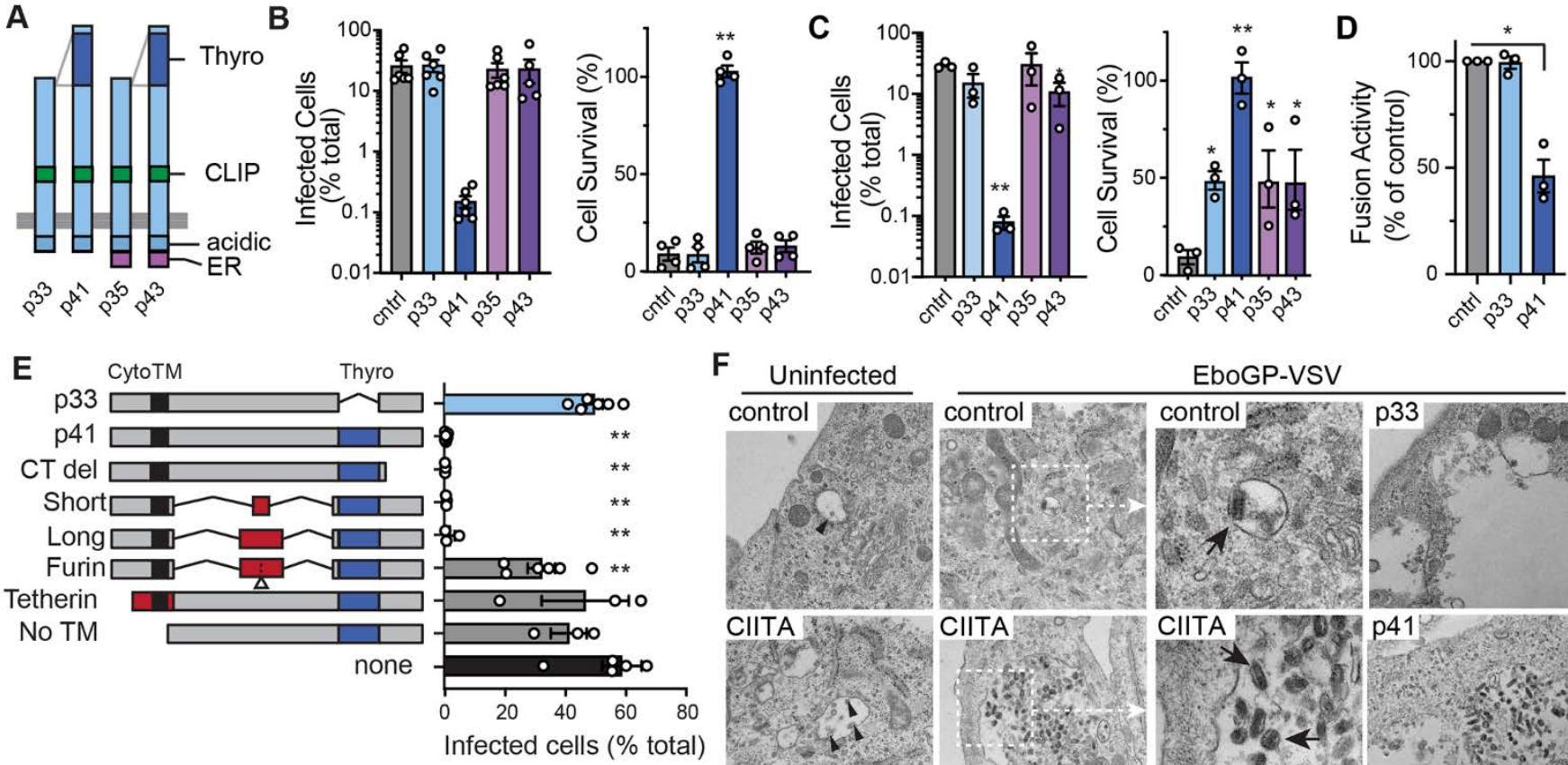

F Uninfected
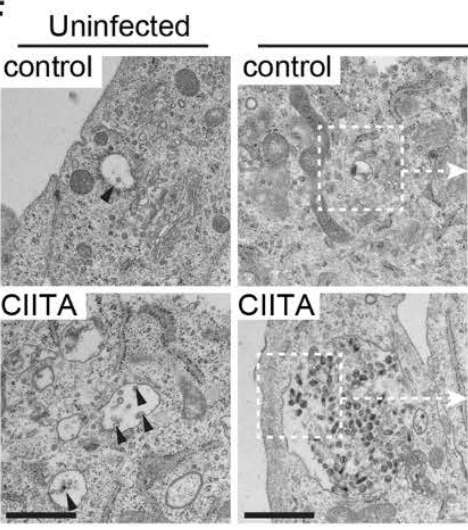

EboGP-VSV

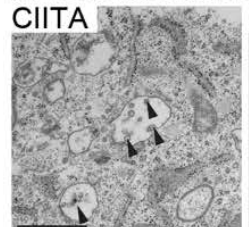

G
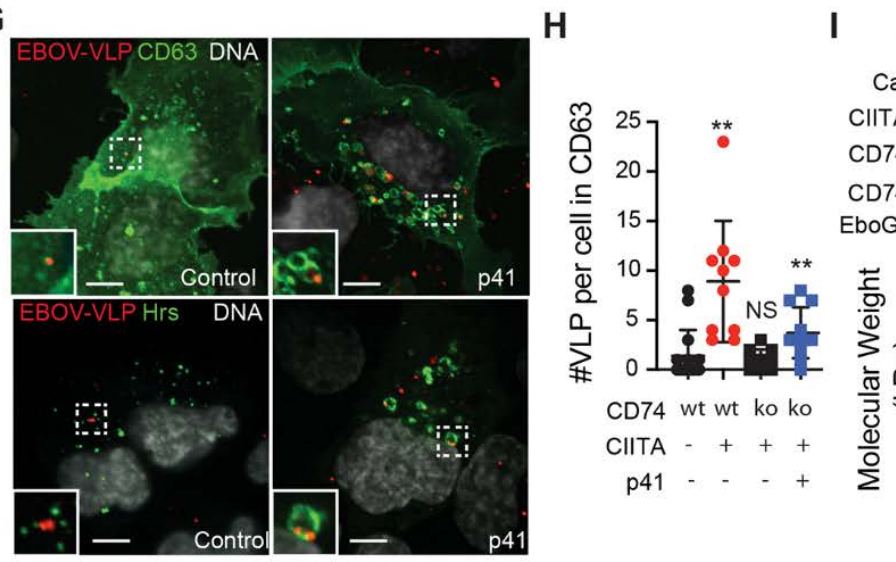

at -

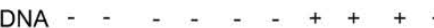

CD74 Crispr - - - - - - + + +

CD74 cDNA - - - - - - - - $\quad-$ p41p33
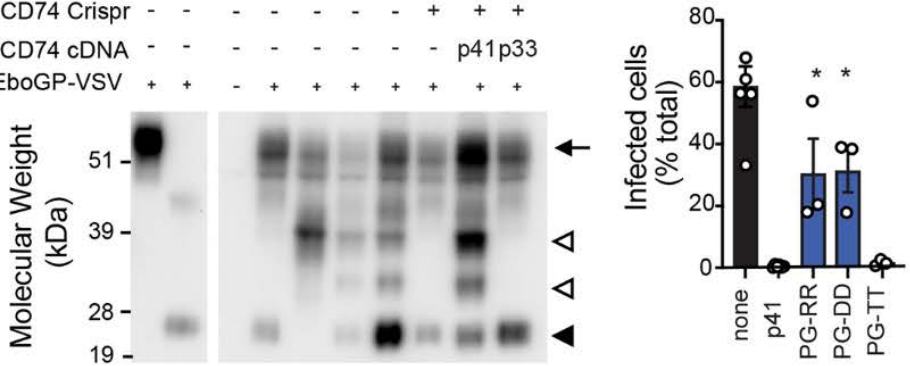

K

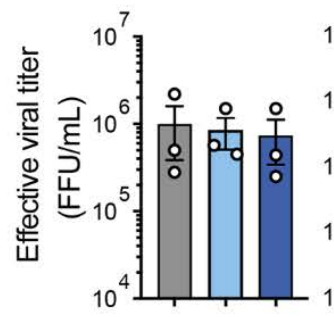

CD74 cDNA: cntrl p33 p41 VSV-G

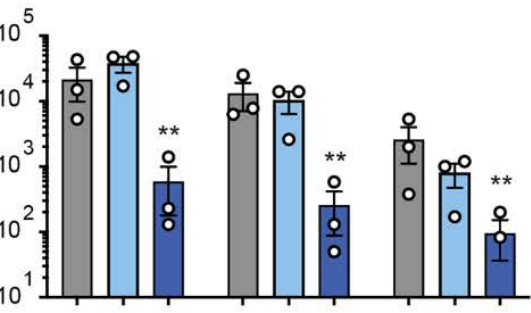

cntl p33 p41 cntlp33 p41 cntlp33 p41 EboGP

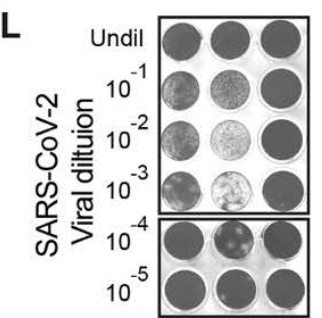

CD74 cDNA: cntrl p33 p41

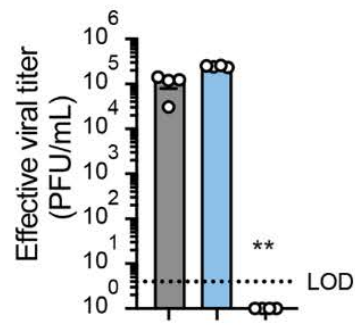

CD74 cDNA: cntrl p33 p41 SARS-CoV-2 
Fig. 4. CD74 p41 inhibits cathepsin-mediated cleavage of EboGP. (A) Human CD74 isoforms with ER-retention signal (ER), CLIP, acidic, and p41 thyroglobulin domains. (B and C) EboGP-VSV infection and survival of Cd74 ${ }^{-/-}$ CIITA-expressing (B) or wt (C) U2OS cells expressing CD74 isoforms. (D) EboGP-VLP fusion in THP-1 macrophage like cells expressing CD74 p33 and p41. (E) EboGP-VSV infection of U2OS cells expressing CD74 mutant constructs. (F) Transmission electron micrographs of control, CIITA-expressing, and CD74-expressing U2OS cells, 3 hours after infection with EboGP-VSV. Dotted line regions enlarged in adjacent panels. Intraluminal vesicles (arrowheads) and internalized EboGP-VSV (arrows) are marked. Scale bars: $1 \mu \mathrm{m}$ (left, center-left, and right panels), $200 \mathrm{~nm}$ (center-right panels). (G) Confocal microscopy of control and p41-expressing U2OS cells showing EBOV-VLP (red), CD63, or Hrs (green), and nuclei (white). Scale bars: $10 \mu \mathrm{m}$. (H) VLPs associated with CD63 endosomes in U2OS cells expressing CIITA and CD74 as indicated. Each point represents a single cell, mean \pm SD $n \geq 9$. Mann-Whitney $U$ test; ${ }^{* *} P<0.01$. Similar results seen in three independent experiments. (I) Immunoblot of EboGP in EboGP-VSV-infected U2OS cells. EboGP-VSV preparation \pm thermolysin (Therm) shown for reference (left). Cells were treated with cathepsin inhibitors E64D (E) or FYDMK (F), or expressed CIITA and CD74. EboGP in virus particles (arrow), after proteolysis (closed arrowhead) and after partial cleavage (open arrowhead) are indicated. (J) EboGP-VSV infection of U2OS cells expressing p41 with CTSL binding site mutations. (K) Infection of control, p33-, or p41-expressing U2OS cells by HIV-GFP pseudotyped with glycoproteins from VSV, EBOV, SARS-CoV, or WIV1-CoV, measured as focus forming units per milliliter of virus (FFU/ml). (L) Infection of control, p33-, or p41-expressing Vero cells by SARS-CoV-2, showing representative crystal violet-stained monolayers and infection measured as plaque-forming units per milliliter of virus $(\mathrm{PFU} / \mathrm{ml})$. Except where indicated, data are mean $\pm \mathrm{SEM}$ of data from $\geq 3$ independent experiments. Student's $t$ test with Benjamini correction; ${ }^{*} P<0.05 ;{ }^{*} P<0.01$. 